\title{
Kinetics and thermodynamics of Bezaktiv Yellow HE-4G on mixture of date pits and olive stone from aqueous solution
}

\author{
H. Babaci, H. Aksas, K. Louhab* \\ Laboratoire de technologie alimentaire -Facultyof engineer science, \\ University of Boumerdes - 35000, Algieria \\ *E-mail address: louhab_ka@yahoo.fr
}

\begin{abstract}
In this paper, the adsorption of an anions dye Bezaktiv Yellow HE-4G onto mixture biosorbent, olive stones and date pits was investigated in aqueous solution. The effect of operational parameter such as initial dye concentration, time contact, temperature and $\mathrm{pH}$ was evaluated. The pseudo firstorder and the pseudo second-order were used to describe the kinetics data. The data were evaluated for compliance with Freundlich and Langmuir models. Biosorptions data were successfully described by Freundlich isotherm model and the pseudo second-order model. Thermodynamic parameters indicated that the biosorption of BY HE-4G onto biosorbent mixture was spontaneous and endothermic in nature. The results indicated that the mixture of date pits and olive stone could be used as an adsorbent for textile waste water treatment without high cost.
\end{abstract}

Keywords: anions dye; sorption; kinetics; olive stone; date pit

\section{INTRODUCTION}

There has been an increase for effluent being disposed to natural water bodies due to rapid industrialization. Major contaminants found in waste water include biodegradable, volatile and recalcitrant organic compounds, toxic metals, suspended solids, plant nutrients, dyes, microbial pathogens and parasites [1].

Colored dye waste water arises as a direct result of the production of the dye and also as a consequence of its use in textile and other industries [2]. The dye waste water from textile mills represents a serious pollution problem because of its high both color and organic content affecting the aquatic flora and fauna [3].

Synthetics dyes used in textile industry are eventually released into effluents that get its way to the environments; about $2 \%$ of dye synthesized are released directly in aqueous effluents and consequently produce a sizeable amount of colored waste water [1].

Azo dyes are synthetic organic compounds widely used in textile dyeing, paper printing and other industrial processes such as the manufacture of pharmaceutical drugs, toys and foods including candies. This chemical class of dyes, which is characterized by the presence of at least one azo bond $(-\mathrm{N}=\mathrm{N}-)$ bearing aromatic rings, dominates the worldwide market 
of dyes tuffs with a share of about 70\% [4].Reactive azo dyes released from textile dyeing plants are highly recalcitrant to conventional waste water treatment processes.

The most widely used methods for removing dyes from waste water systems include physicochemical, chemical and biological methods, such as flocculation, coagulation, precipitation, adsorption, membrane filtration, electrochemical techniques, ozonation and fungal decolorisation.

However, waste waters containing various dyes are very difficult to treat using conventional waste water treatment methods, since the dyes are generally stable under the influence of light and oxidizing agents [5].

Of the numerous techniques mentioned, adsorption in particular is an effective process for the removal of dyes from waste effluents: it is low-cost, highly efficient, simple, easy to perform and insensitive to toxic substances [6]. Biosorption is usually fast method and make use of cheaper materials; for instance waste biomass from agriculture and industry being plenteous in nature, economical and require minute processing.

Biosorption is a finishing technology and it reduces the concentration of dyes in bulky volumes of wastewaters to very small levels [6].

This research paper illustrates the use of different mixture of date pits waste and olive stone waste in their native form for the removal of reactive textile dye (Bezaktiv yellow HE $4 \mathrm{G})$. The factors studied are initial dye concentration, $\mathrm{pH}$, temperature, and contact time. The isotherm, kinetic and thermodynamics of dye adsorption were studied.

\section{MATERIALS AND METHODS}

\subsection{Dye characterization}

Dye used in this study is Bezaktiv yellow HE- 4G obtained from firm Bezema Suisse. It is a monochlorotriazoique, the maximum adsorption wavelength of this dye is $360 \mathrm{~nm}$.

\subsection{Adsorbents}

Preparation of sorbent: date pits were obtained from southern of Algeria and olive stones from northern of Algeria were used as starting material. The olive stones first washed with water to remove the adhering dirt and then it were input in hexane for 24 hours to eliminate residual oil, and then were washed with distilled water and then were dried. Date pits were washed and dried. The dried olive stones and date pits were then crushed, milled and sieved into different particle sizes. Studies were focused on a size fraction of 0.4 to 0.8 $\mathrm{mm}$. the olive stone waste with date pits waste are mixed at different percentage. In this study, we used five samples such that their composition is given in table 1. 
Table 1. Percentage of olive stone and date pits in different mixture.

\begin{tabular}{|c|c|c|}
\hline Sample number & Percent of olive stone & Percent of date pits \\
\hline 1 & 100 & 0 \\
2 & 0 & 100 \\
3 & 88 & 12 \\
4 & 85 & 15 \\
5 & 80 & 20 \\
6 & 66 & 34 \\
7 & 60 & 40 \\
\hline
\end{tabular}

\subsection{Adsorption studies}

The dye stock solution was prepared by dissolving accurately $1 \mathrm{~g}$ amounts of dye into $1000 \mathrm{ml}$ of distilled water and the experimental solutions were obtained by diluting the stock solution to the required concentrations. Adsorption experiments were performed at different dye concentrations $(100,200,300,400,500,600$ and $700 \mathrm{mg} / 1)$ using $0.2 \mathrm{~g}$ adsorbent mixture and $15 \mathrm{ml}$ of dye solution in a conical flask. The conical was then shaken at a constant speed of $350 \mathrm{rpm}$ at $\mathrm{pH} 5.6$ at $20 \mathrm{C}^{\circ}$. The initial $\mathrm{pH}$ value was adjusted to $3,5,8$ and 10 with $0.1 \mathrm{M} \mathrm{HCl}$ or $1.0 \mathrm{M} \mathrm{NaOH}$. The effect of temperature on sorption was studied using four different temperatures $20,30,40$ and $50 \mathrm{C}^{\circ}$. At the end of experiments biosorbent dye mixtures were centrifuged at $5000 \mathrm{rpm}$ for $3 \mathrm{~min}$ and the supernatants were analyzed spectrophotometrically at $360 \mathrm{~nm}$ to determine the residual concentration of reactive dye.

The amount of dye sorbet by weight of dry mixture wastes was calculated by the relationship:

$$
\mathrm{Qt}=(\mathrm{Ci}-\mathrm{Ct}) \times v / m
$$

Where $\mathrm{Ci}$ and $\mathrm{Ct}\left(\mathrm{mg} \cdot \mathrm{L}^{-}\right.$) are initial dye and at time $\mathrm{t}$ dye solution concentration respectively, $\mathrm{v}(\mathrm{L})$ is the solution volume and $\mathrm{m}(\mathrm{g})$ is the dry weight of the sorbent.

\section{RESULTS AND DISCUSSION}

\subsection{Effect of contact time}

From an economical point of view, the contact time required to reach equilibrium is an important parameter in wastewater treatment [7].

The amount of Bezaktiv yellow HE - $4 \mathrm{G}$ onto mixture adsorbent is given as a function of time ( 1 to $30 \mathrm{~min}$ ) in fig 1 . The adsorption of dye is rapid in the initial stages of contact time and gradually decreased with lapse of time until equilibrium. The optimal removal efficiency was reached within about $15 \mathrm{~min}$. There was no significant change in equilibrium concentration after $15 \mathrm{~min}$. The rapid adsorption at the initial contact time can be explained by the availability of the positively charged surface of the sorbent mixture that led to fast electrostatic attraction of the anionic Bezaktiv yellow HE-4G from the solution.

It is clear from the figure that the reaction of adsorption nearly reached equilibrium within $30 \mathrm{~min}$. 


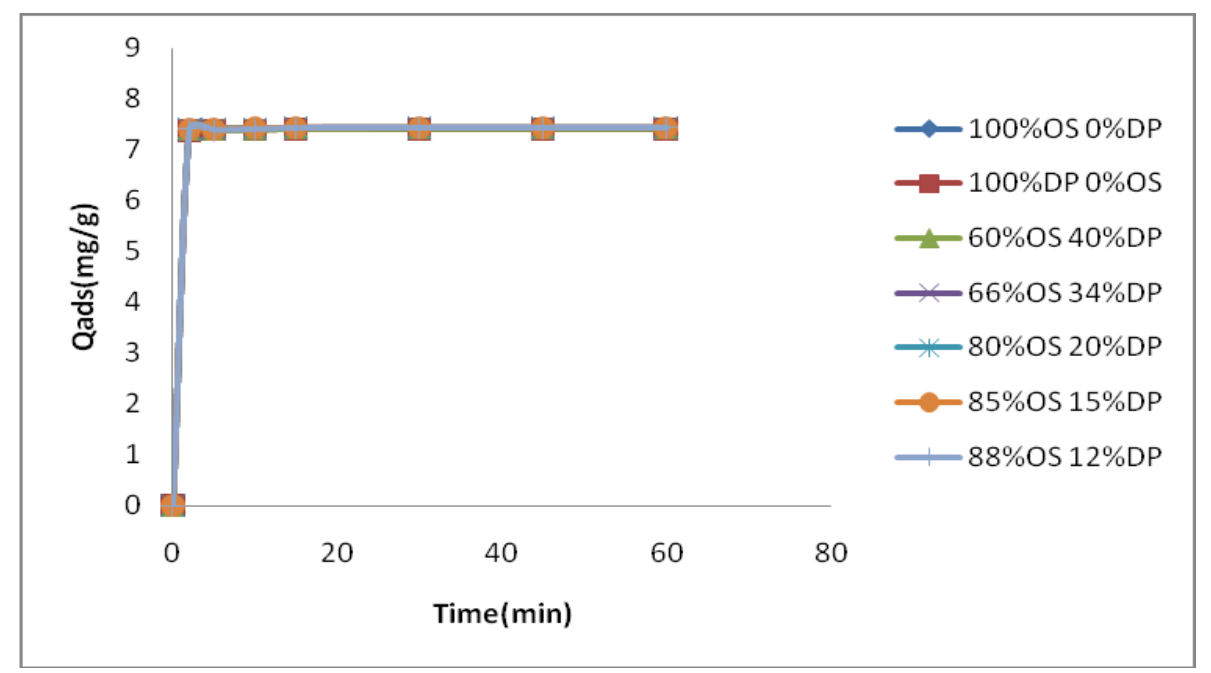

Fig. 1. Effect of contact time on sorption kinetics of BY HE-4G adsorption by mixture sorbent $\left(\mathrm{C}_{0} 0.1 \mathrm{~g} / 1, \mathrm{pH} 5.6, \mathrm{t}^{\circ} 20^{\circ}, \mathrm{m}\right.$ adsorbent $\left.0.2 \mathrm{~g}, 350 \mathrm{rpm}\right)$.

\subsection{Effect of initial dye concentration}

The initial dye concentration provides an important driving force to overcome all mass transfer resistances of dyes between the aqueous and solid phases [8]. The kinetics of adsorption of Bezaktiv yellow HE-4G onto different mixture biosorbent at different initial concentrations was achieved. Figure 2 shows the extent of dye adsorption as function of reaction time. The experiment were done at different dye concentrations $(100,300,500,700,900$ and $1000 \mathrm{mg} / \mathrm{L})$. It was found that, when the initial concentration increases, the amount of dye adsorbed per gram amount of adsorbent increase, the results are shown in figure 2 . The value of $\mathrm{q}$ increase from 7.425 to $37.056 \mathrm{mg} / \mathrm{g}$ when increasing of the initial dye concentration dye from 0.1 to $0.5 \mathrm{mg} / 1$. Then it can be attributed that the active sites on adsorbent for dye removal decreases when dye concentration increases. The kinetics adsorption curves are smooth and continuous leading to saturation of biosorbent mixtures by BY HE-4G. This result suggests the possibility of -layer coverage adsorption of RY HE-4G on biosorbent mixtures [9]. This phenomena is illustrated in figure3.

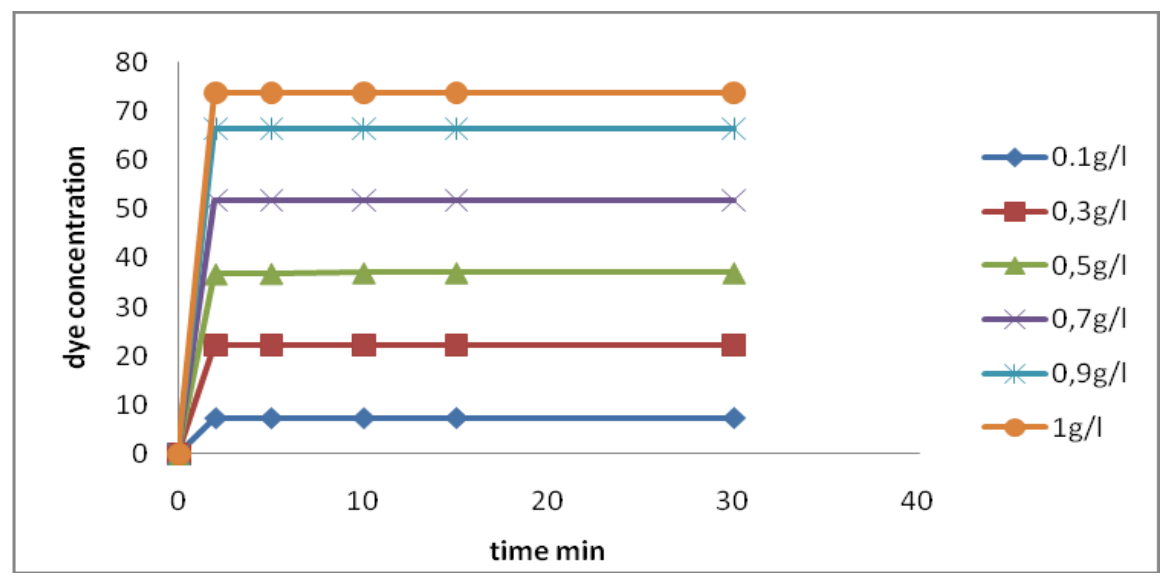

Fig. 2. Effect of dye concentration on amount of dye removal by biosorbent on sample 6 (p H 5.6,T $\left.20 \mathrm{C}^{\circ}, 350 \mathrm{rpm}\right)$. 


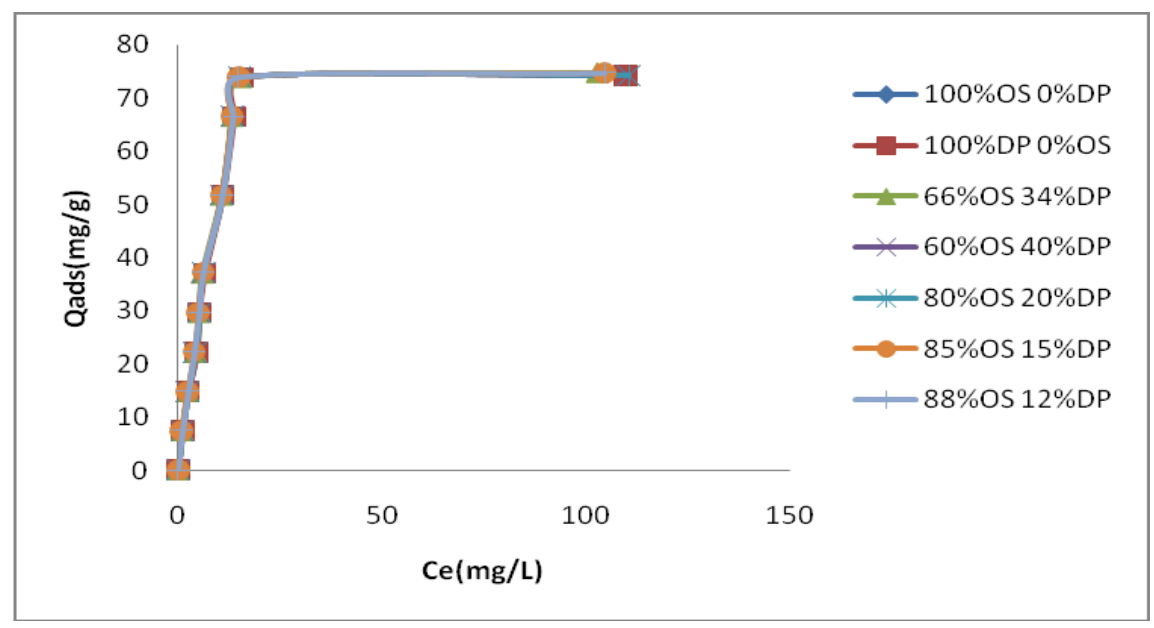

Fig. 3. Adsorption isotherm.

\subsection{Effect of pH}

The wastewater from textile industries usually has a wide range of $\mathrm{pH}$ values. This $\mathrm{pH}$ of the system plays an important role in the textile wastes treatment [10]. The effect of solution $\mathrm{pH}$ on Bezaktiv yellow HE-4G adsorption by adsorbent mixture was studied at the $\mathrm{pH}$ ranges of 2 to 10 and the results are given in figure 4 . This figure indicates that an increase in the initial $\mathrm{pH}$ has a negative effect on the removal capacity of biosorbent. Lower adsorption of Bezaktiv Yellow HE-4G (anionic dye) at alkaline $\mathrm{pH}$ is probably due to the presence of excess of $\mathrm{OH}^{-}$ions competing with the dye anions for the adsorption sites. Therefore maximum biosorption capacity has found to be average $74 \mathrm{mg} / \mathrm{g}$ in the rage of 2 to 6 . At the acidic $\mathrm{pH}$, the number of positively charged sites increase, which favors the adsorption of the anions due to electrostatic attraction.

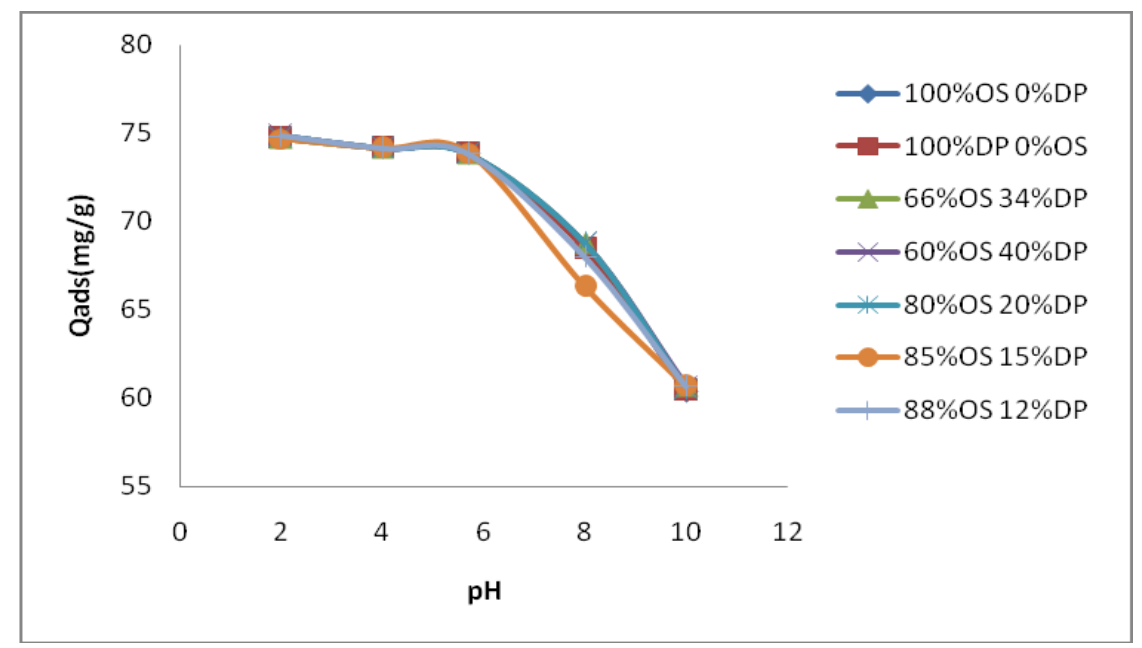

Fig. 4. Effect of $\mathrm{pH}$ on the adsorption of Bezaktiv yellow $\mathrm{HE}-4 \mathrm{G}$ on mixture biosorbent. $\left(\mathrm{C}_{0} 1 \mathrm{~g} / \mathrm{l}, \mathrm{T} 20 \mathrm{c}^{\circ}\right)$. 


\subsection{Effect of temperature}

The temperature has two major effects on the adsorption process. Increasing the temperature is known to increase the rate of diffusion of the adsorbed molecules across the external boundary layer and the internal pores of the adsorbent particles owing to the decrease in the viscosity of the solution [9]. The removal of the BY HE-4G increase from 73.84 to 74.9 $\mathrm{mg} / \mathrm{g}$ by increasing the temperature of the solution from 20 to $50 \mathrm{c}^{\circ}$, indicating that the process to be endothermic. The results are shown in figure 5 .

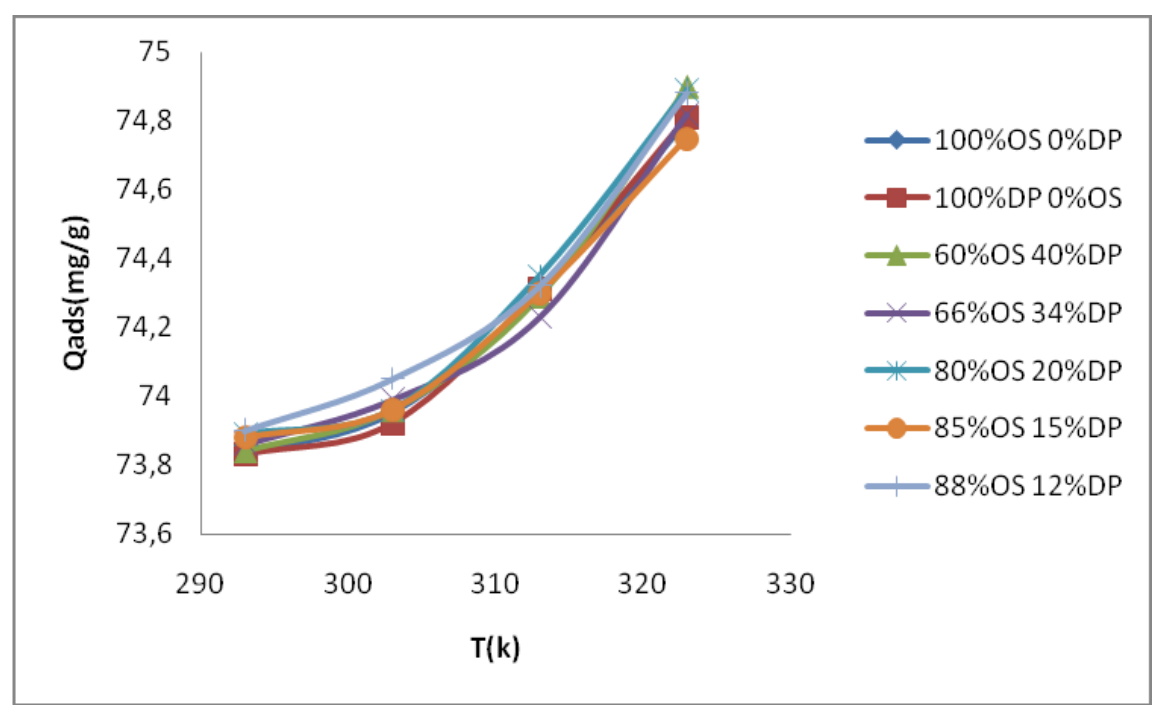

Fig. 5. Effect of temperature on the removal of adsorption of BY HE-4G. $\left(\mathrm{C}_{0} 1 \mathrm{~g} / \mathrm{l}, \mathrm{pH}\right.$ 5.6)

\subsection{Adsorption kinetic studies}

The kinetic investigation is performed to determine the effiency of dye adsorption onto adsorbent. The several kinetic models are usec to examine the biosorption mechanism such as mass transfer and chemical reaction. One of them is Lagergren's pseudo-first-order model and it assumes that the occupation rate of biosorption sites is proportional to the number of unoccupied sites [11, 12]. A linear form of pseudo-first-order model (equation 2) is:

$$
\ln \left(q_{\theta}-\mathrm{q}_{\mathrm{t}}\right)=\ln \mathrm{q}_{\mathrm{e}}-\mathrm{k}_{1} \cdot \mathrm{t}
$$

Where $\mathrm{q}_{\mathrm{e}}$ and $\mathrm{q}_{\mathrm{t}}$ are the amount of biosorbed BY HE-4G on biosorbent mixture at equilibrium and at time $\mathrm{t}\left(\mathrm{mg} \mathrm{g}^{-}\right)$respectively. $\mathrm{k}_{1}$ is the pseudo-first-order rate constant $\left(\min ^{-}\right)$. The value of $\mathrm{K}_{1}$ and $\mathrm{q}_{\mathrm{e}}$.were calculated from slope and intercept, respectively, of the plot of $\ln \left(\mathrm{q}_{\mathrm{e}}-\mathrm{q}_{\mathrm{t}}\right)$. 


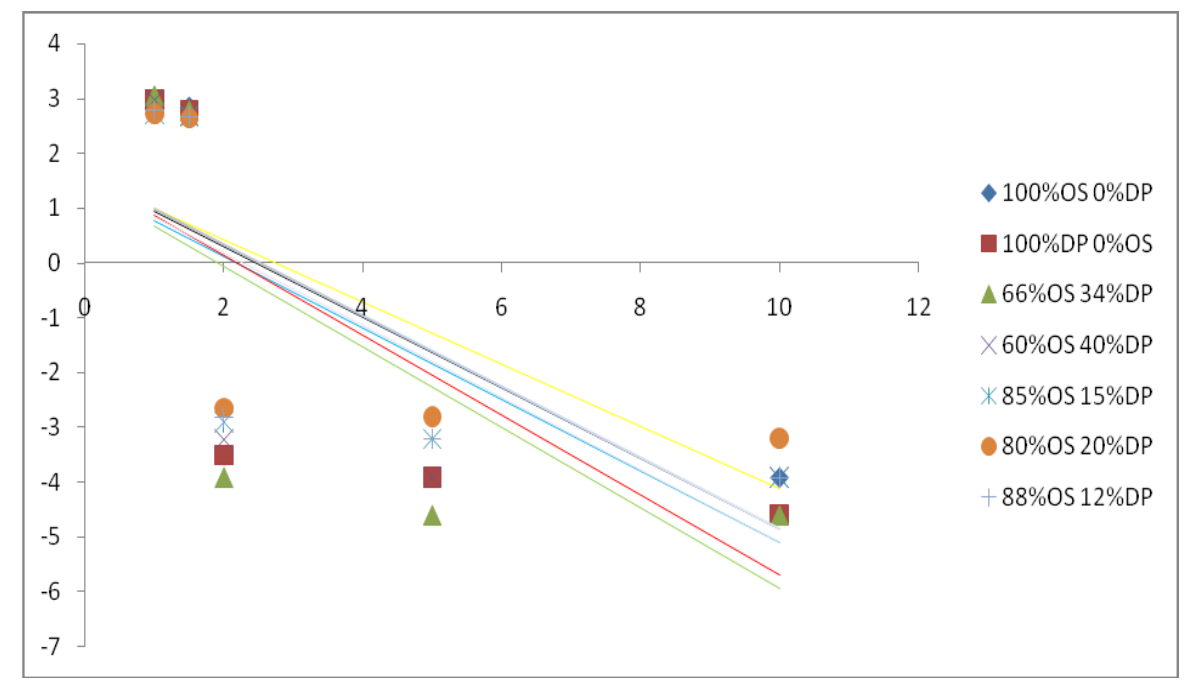

Fig. 6. Plot of pseudo-first order kinetic model BY HE-4G adsorption onto mixture biosorbent. $\left(\mathrm{C}_{0}=1000 \mathrm{mg} / \mathrm{g}\right)$.

The pseudo-second -order kinetic equation ${ }^{13}$ is expressed as:

$$
\frac{t}{q_{t}}=\frac{1}{k_{2} q_{2}^{2}}+\frac{1}{q_{2} t}
$$

Where $\mathrm{k}_{2}$ is the rate constant of pseudo-second-order kinetic model (g.mg $\left.{ }^{-} \cdot \mathrm{min}^{-}\right)$. Values of $\mathrm{k}_{2}$ and $\mathrm{q}_{2}$ were calculated from a plot of $\mathrm{t} / \mathrm{q}_{\mathrm{t}}$ against $\mathrm{t}$. figure 7 .All the results are listed in table 2 .

Table 2. Kinetic parameters for dye adsorption at $1000 \mathrm{mg} / \mathrm{L}$ dye concentration.

\begin{tabular}{|c|c|c|c|c|c|c|c|}
\hline \multirow{3}{*}{ Samples } & \multirow{2}{*}{$\begin{array}{c}\mathrm{q}_{\exp } \\
\mathrm{mg} / \mathrm{g}\end{array}$} & \multicolumn{3}{|c|}{ Pseudo- first -order } & \multicolumn{3}{c|}{ Pseudo -second -.order } \\
\cline { 3 - 8 } & & $\begin{array}{c}\mathrm{q}_{\mathrm{ecal}} \\
\mathrm{mg} / \mathrm{g}\end{array}$ & $\mathrm{K}_{1}$ & $\mathrm{R}^{2}$ & $\begin{array}{c}\mathrm{q}_{\text {ecal }} \\
\mathrm{mg} / \mathrm{g}\end{array}$ & $\mathrm{K}_{2}$ & $\mathrm{R}^{2}$ \\
\hline 1 & 73.84 & 4.137 & 0.652 & 0.452 & 76.92 & 0.169 & 0.999 \\
2 & 73.86 & 4.95 & 0.730 & 0.520 & 76.92 & 0.0845 & 0.999 \\
3 & 73.88 & 5.10 & 0.648 & 0.535 & 76.92 & 0.169 & 1 \\
4 & 73.83 & 4.90 & 0.644 & 0.525 & 76.92 & 0.169 & 1 \\
5 & 73.83 & 4.72 & 0.567 & 0.484 & 76.92 & 0.169 & 1 \\
6 & 73.86 & 4.06 & 0.730 & 0.471 & 76.92 & 0.169 & 0.999 \\
7 & 73.83 & 4.49 & 0.660 & 0.478 & 76.92 & 0.0845 & 0.999 \\
\hline
\end{tabular}

According to high $\mathrm{R}^{2}$ values $\left(\mathrm{R}^{2}=1\right)$ in table 2 , the pseudo-second-order kinetic model showed satisfactory fits. The $\mathrm{q}_{\mathrm{e}}$ values estimated from the pseudo-second-order-kinetic model were also good agreement with the experimental values. These finding indicated that the pseudo-second order kinetic model is more suitable to describe the BY HE-4G biosorption into biosorbent mixture. 


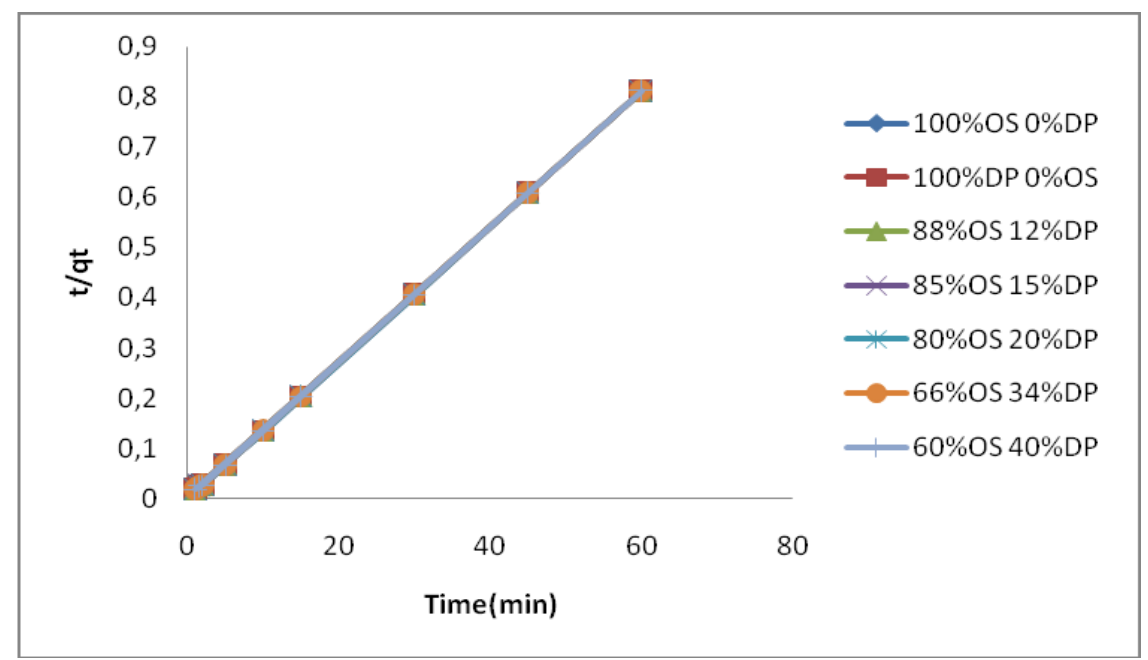

Fig. 7. Plot of pseudo - second order kinetic model for BY HE-4G adsorption onto mixture biosorbent.

In order to evaluate the equilibrium data in this study, the Freundlich (equation 4), Langmuir (equation 5), isotherm models were employed. The Langmuir theory assumes a homogenous type of sorption. It is meaning that once a dye molecule occupies a binding site, no further adsorption can take place at that site. Freundlich model assumes that adsorption takes place on heterogeneous surfaces with a non uniform distribution of heat of adsorption over the surface.

The linearized forms of the model equations are given below:

$$
\begin{gathered}
\ln \mathrm{q}_{\mathrm{e}}=\ln \mathrm{k}_{\mathrm{f}}+1 / \mathrm{n} \ln \mathrm{C}_{\mathrm{e}} \\
\mathrm{C}_{\mathrm{e}} / \mathrm{q}_{\mathrm{e}}=1 / \mathrm{q}_{\max } \cdot \mathrm{b}+\left(1 / \mathrm{q}_{\max }\right) \cdot \mathrm{C}_{\mathrm{e}}
\end{gathered}
$$

In equation 4 qe (mol.g- ${ }^{1}$ ) and $\mathrm{C}_{\mathrm{e}}\left(\mathrm{mol}_{\mathrm{L}} \mathrm{L}^{-1}\right)$ are the dye equilibrium concentrations in the solid and liquid phases; $\mathrm{k}_{\mathrm{f}}\left(\mathrm{L} . \mathrm{g}_{-}{ }^{1}\right)$ and $\mathrm{n}$ are characteristic constants that indicate the extent of biosorption, and the degree of non linearity between solution concentration and biosorption respectively. The values of $\mathrm{k}_{\mathrm{f}}$ and $1 / \mathrm{n}$ are determined from the intercept and slope of the Freudlish plots figure 8 .

In equation (5) qmax is the monolayer biosorption capacity of the biosorbent(mol.g- $\left.{ }^{1}\right)$; and $b$ is the Langmuir constant $\left(\mathrm{Lmol}^{-1}\right)$ and is related to the free energy . The values of $q_{\max }$ and $b$ are determined from the intercept and slope of the Langmuir plots figure 9.

The essential features of a Langmuir isotherm can be expressed in terms of a dimensionless constant separation factor or equilibrium parameter, $\mathrm{R}_{\mathrm{L}}$ defined as:

$$
\mathrm{R}_{\mathrm{L}}=1 /(1+\mathrm{bC})
$$

The value of $R_{L}$ indicates the shape of isotherms to be either unfavourable $\left(R_{L}>1\right)$, linear $\left(\mathrm{R}_{\mathrm{L}}=1\right)$, favourable $\left(0<\mathrm{R}_{\mathrm{L}}<1\right)$ or irreversible $\left(\mathrm{R}_{\mathrm{L}}=0\right)$.

The determined parameter values for the isotherm models are given in table 3 . 
The results indicated that isotherm data of BY HE-4G followed Freundlich isotherm models. The value of $\mathrm{R}_{\mathrm{L}}$ for the adsorption of $\mathrm{BY}$ HE-4G greater than zero and less than unity showing favorable sorption of BY HE-4G onto the mixture of biosorbent.

Table 3. Equilibrium constants for adsorption into mixture biosorbent.

\begin{tabular}{|c|c|c|c|c|c|c|c|c|}
\hline \multirow{2}{*}{ Samples } & & \multicolumn{4}{|c|}{ Langmuir constants } & \multicolumn{3}{c|}{ Freundlich constants } \\
\cline { 3 - 9 } & $\mathrm{q}_{\text {exp mg/g }}$ & $\mathrm{q}_{\operatorname{max~mg} / \mathrm{g}}$ & $\mathrm{b}$ & $\mathrm{R}^{2}$ & $\mathrm{R}_{\mathrm{L}}$ & $\mathrm{n}$ & $\mathrm{K}_{\mathrm{f}}$ & $\mathrm{R}_{\mathrm{F}}^{2}$ \\
\hline & & & & & & & & \\
1 & 73.83 & 333.33 & 0.018 & 0.676 & 0.052 & 0.873 & 0.112 & 0.993 \\
2 & 73.83 & 333.33 & 0.018 & 0.646 & 0.052 & 0.881 & 0.118 & 0.994 \\
3 & 73.88 & 250 & 0.026 & 0.745 & 0.037 & 1.156 & 6.91 & 0.993 \\
4 & 73.88 & 200 & 0.037 & 0.732 & 0.026 & 0.910 & 0.124 & 0.978 \\
5 & 73.90 & 250 & 0.027 & 0.720 & 0.035 & 1.18 & 7.24 & 0.994 \\
6 & 73.84 & 250 & 0.027 & 0.709 & 0.035 & 0.857 & 0.100 & 0.993 \\
7 & 73.86 & 250 & 0.027 & 0.672 & 0.035 & 1.204 & 7.644 & 0.985 \\
& & & & & & & & \\
\hline
\end{tabular}

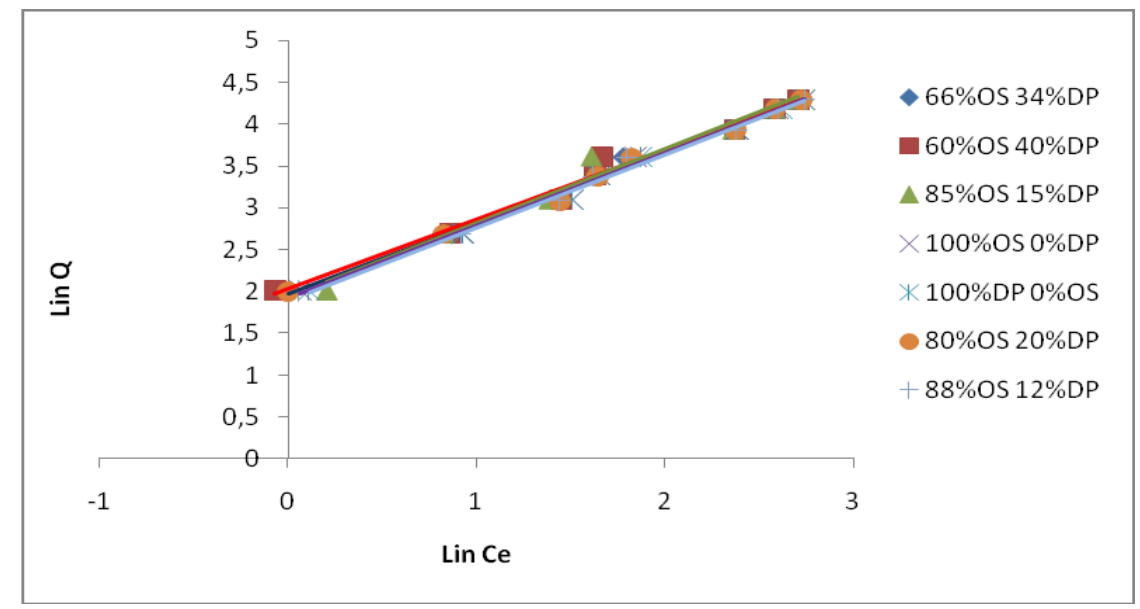

Fig. 8. Freundlich isotherm plot for the biosorption of BY HE-4G onto biosorbent mixture.

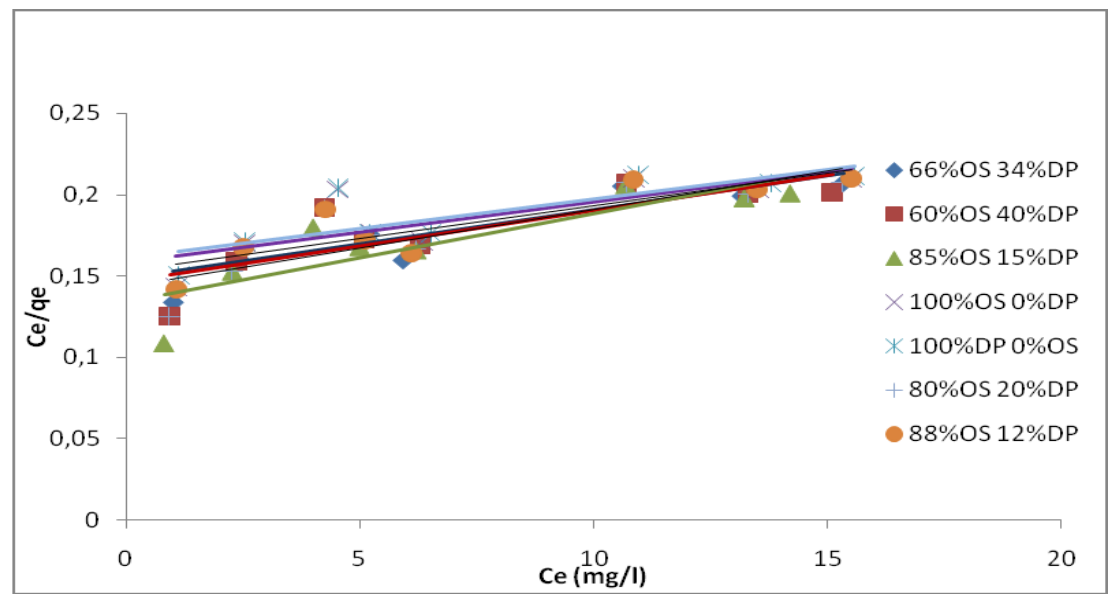

Fig. 9. Langmuir isotherm plot for the biosorption of BY HE-4G onto biosorbent mixture. 


\section{Intra particule diffusion model}

The possibility of intraparicule diffusion resistance affecting adsorption was explored by using the intraparticule diffusion model.

$$
\mathrm{q}_{\mathrm{t}}=\mathrm{k}_{\mathrm{int}} \cdot \mathrm{t}^{1 / 2}+\mathrm{x}_{\mathrm{i}}
$$

Where $\mathrm{q}_{\mathrm{t}}, \mathrm{k}_{\mathrm{int}}$ and $\mathrm{x}_{\mathrm{i}}$ are amount of dye adsorbent $(\mathrm{mg} / \mathrm{g})$ at time $\mathrm{t}(\mathrm{min})$. The results are shown in table 4. and fig. 10.

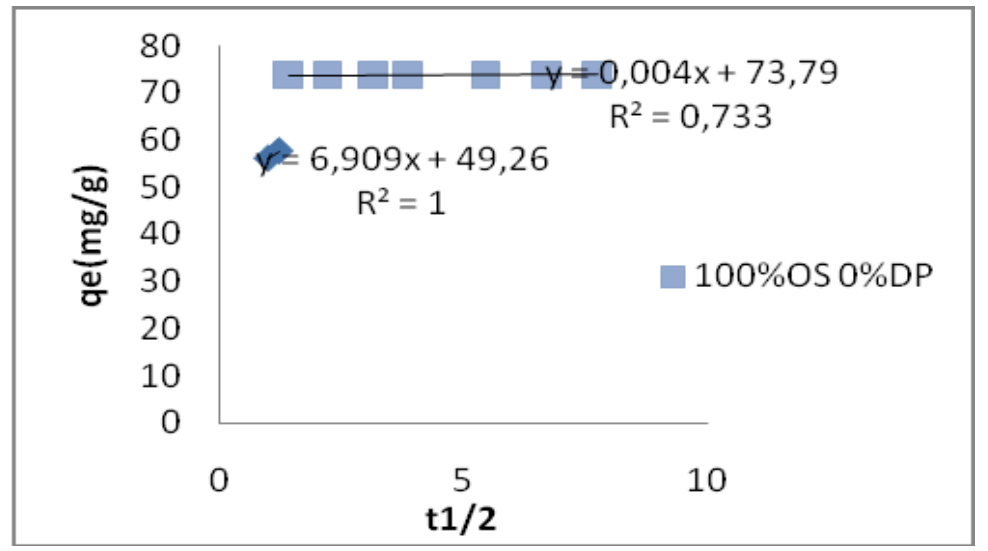

Fig. 10. Intra particule diffusion model $\left(\mathrm{c}_{0} 1000 \mathrm{mg} / 1, \mathrm{~T}^{\circ} 20 \mathrm{C}^{\circ}\right.$, sample 1).

Table 4. Results of intra particule diffusion model.

\begin{tabular}{|c|c|c|c|c|}
\hline Samples & Time $(\mathrm{min})$ & $\mathrm{K}_{\text {int }}\left(\mathrm{mg} / \mathrm{g} \cdot \mathrm{min}^{1 / 2}\right)$ & $\mathrm{X}_{\mathrm{i}}(\mathrm{mg} / \mathrm{g})$ & $\mathrm{R}^{2}$ \\
\hline \multirow{3}{*}{1} & 1 à 1.5 & 6.909 & 49.26 & 1 \\
\cline { 2 - 5 } & 2 à 60 & 0.004 & 73.80 & 0.733 \\
\hline \multirow{3}{*}{2} & 1 à 1.5 & 15.59 & 38.44 & 1 \\
\cline { 2 - 5 } & 2 à 60 & 0.004 & 73.90 & 0.656 \\
\hline \multirow{3}{*}{3} & 1 à 1.5 & 7.818 & 49.98 & 1 \\
\cline { 2 - 5 } & 2 à 60 & 0.004 & 73.80 & 0.656 \\
\hline \multirow{3}{*}{4} & 1 à 1.5 & 3.681 & 54.78 & 1 \\
\cline { 2 - 5 } & 2 à 60 & 0.007 & 73.83 & 0.723 \\
\hline \multirow{3}{*}{5} & 1 à 1.5 & 6.045 & 52.42 & 1 \\
\cline { 2 - 5 } & 2 à 60 & 0.009 & 29.83 & 0.643 \\
\hline \multirow{3}{*}{6} & 1 à 1.5 & 23 & 73.82 & 0.699 \\
\cline { 2 - 5 } & 2 à 60 & 0.002 & 36.06 & 1 \\
\hline \multirow{3}{*}{7} & 1 à 1.5 & 18.27 & 73.82 & 0.699 \\
\cline { 2 - 5 } & 2 à 60 & 0.005 & & 1 \\
\hline
\end{tabular}




\section{Dubinin-Radushkevich(D_R) isotherm}

The D-R isotherm model does not assume a homogenous surface or constant sorption potential [14]. It was applied to estimate the porosity apparent free energy and the characteristic of adsorption and it has commonly been applied in the following form eq (8) and its linear form can be shown in eq (9).

$$
\begin{gathered}
\mathrm{q}_{\mathrm{e}}=\mathrm{Q}_{\mathrm{m}} \exp \left(-\mathrm{k} \varepsilon^{2}\right) \\
\ln \mathrm{q}_{\mathrm{e}}=\ln \mathrm{Q}_{\mathrm{m}}-\mathrm{k} \varepsilon^{2}
\end{gathered}
$$

Where $\mathrm{k}$ is a constant related to the adsorption energy, $\mathrm{Q}_{\mathrm{m}}$ the theoretical saturation capacity, and $\varepsilon$ is the Polanyi potential that can be calculated from eq(10).

$$
\varepsilon=\mathrm{RT} \ln \left(1+1 / \mathrm{C}_{\mathrm{e}}\right)
$$

The plot of $\ln \mathrm{q}_{\mathrm{e}}$ versus $\varepsilon^{2}$ of the experimental data for the adsorption of BY HE $-4 \mathrm{G}$ onto the mixture of bioadsorbent is shown onto fig .11, the slope gives $\mathrm{K}\left[\mathrm{mol}^{2} .\left(\mathrm{kj}^{2}\right)^{-1}\right]$ and the intercept yields the adsorption capacity, $\mathrm{Q}_{\mathrm{m}}\left(\mathrm{mg} \mathrm{g}^{-1}\right)$.the mean free energy of adsorption $(\mathrm{E})$ ,defiened as the free energy change when one mole of ion is transferred from infinity in solution to the surface of the sorbent. E was calculated from the k value using the following relation eq (11).

$$
\mathrm{E}=1 / \sqrt{ } 2 \mathrm{k}
$$

The calculated D-R constants for the adsorption of BY HE-4G onto mixture of biosorbent are shown in fig 11 and table 5.

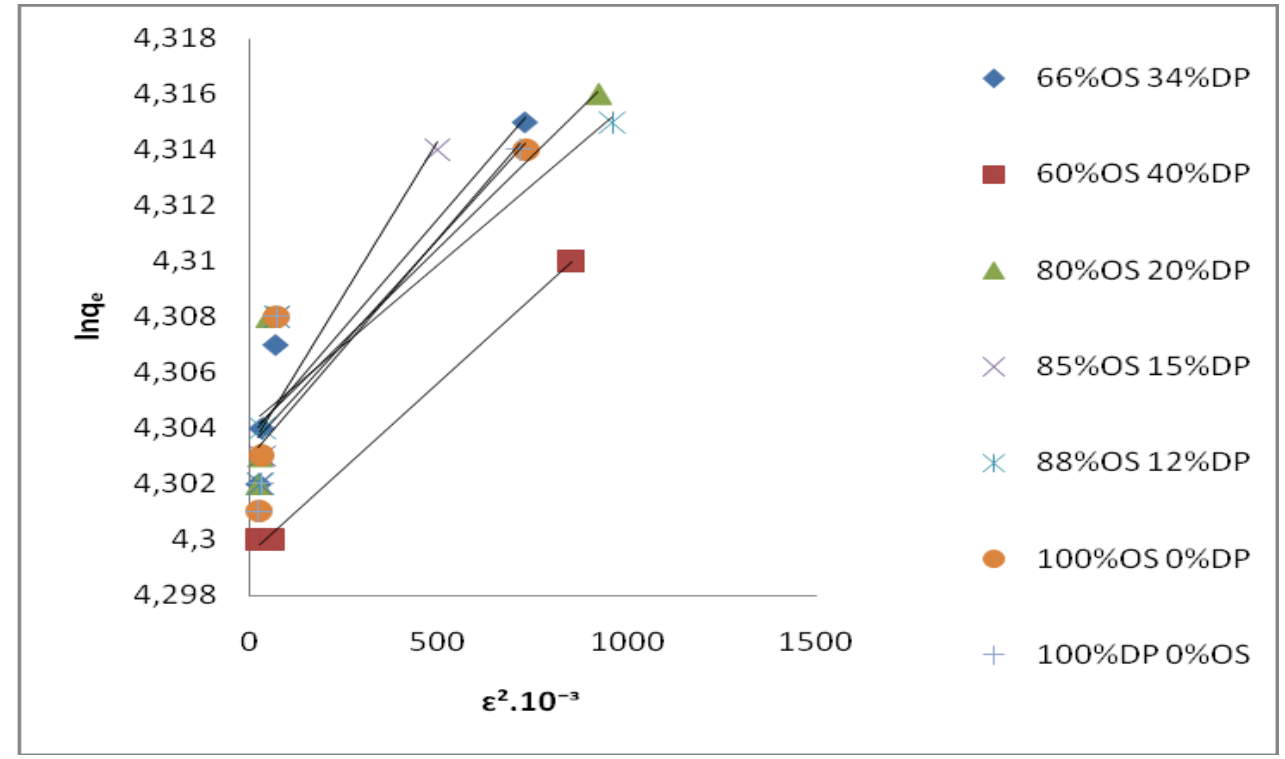

Fig. 11. D-R isotherm model for the adsorption of BY HE-4G onto biosorbent mixture. 
Table 5. D-R constants for the adsorption of BY HE-4G onto mixture of biosorbent.

\begin{tabular}{|c|c|c|c|c|}
\hline Samples & $\mathrm{Q}_{\mathrm{m}} \mathrm{mg} / \mathrm{g}$ & $\begin{array}{c}\mathrm{K}\left(\mathrm{mol}^{2} \mathrm{kj}^{2}\right) \\
.10^{-3}\end{array}$ & $\mathrm{E} \mathrm{Kj} / \mathrm{mol}$ & $\mathrm{R}^{2}$ \\
\hline 1 & 73.92 & 6.7 & 0.115 & 0.792 \\
\hline & & & & \\
\hline 3 & 73.84 & 13.4 & 0.163 & 0.788 \\
\hline 4 & 73.99 & 6.7 & 0.115 & 0.842 \\
\hline 5 & 73.92 & 6.7 & 0.115 & 0.850 \\
\hline 6 & 73.92 & 13.4 & 0.163 & 0.905 \\
\hline 7 & 73.62 & 6.7 & 0.115 & 0.988 \\
\hline
\end{tabular}

The maximum adsorption capacity $\mathrm{Q}_{\mathrm{m}}$ obtained using $\mathrm{D}-\mathrm{R}$ isotherm model is similar as experimental values the value of $\mathrm{E}$ calculated $(\mathrm{E}<8 \mathrm{KJ} / \mathrm{mol})$ indicating that physisorption play a significant role in the adsorption process of BY HE-4G onto biosorbent mixture.

\subsection{Thermodynamic parameters}

The thermodynamic data reflect the feasibility and spontaneous nature of adsorption process. The parameters such as free energy change $\left(\Delta \mathrm{G}^{-}\right)$, enthalpy change $\left(\Delta \mathrm{H}^{-}\right)$and entropy change $(\Delta S)$ can be estimated by equilibrium constants changing with temperature. They were evaluated using the following equations and can be calculated from a plot $\ln \mathrm{k}_{1}$ against $1 / \mathrm{T}$. The results were shown in figure (12)and table (6).

$$
\begin{gathered}
\Delta \mathrm{G}=-\mathrm{RT} \ln \mathrm{K}_{\mathrm{L}} \\
\ln \mathrm{K}_{\mathrm{L}}=-\Delta \mathrm{G} / \mathrm{RT}=-\Delta \mathrm{H} / \mathrm{RT}+\Delta \mathrm{S} / \mathrm{R}
\end{gathered}
$$

Where $\mathrm{K}_{\mathrm{L}}$ is the Langmuir isotherm constant, $\mathrm{R}$ is the universal gas constant $(8.314$ j. $\left.\mathrm{mol}^{-} \cdot \mathrm{K}^{-}\right)$and $\mathrm{T}$ is temperature $(\mathrm{K})$.

The positive value of $\Delta \mathrm{S}$ suggests increase randomness at solid/ solution interface occurs in the internal structure of the adsorption of the BY HE-4G onto biosorbent mixture. The negative value of $\Delta \mathrm{G}$ suggests that the adsorption of BY HE-4G onto biosorbent mixture is a spontaneous process. The positive value of $\Delta \mathrm{H}$ shows the adsorption is an endothermic process. 
Table 6. Value of the thermodynamic of adsorption at various temperatures $\left(\mathrm{C}_{0}=1000 \mathrm{mg} / \mathrm{L}\right)$.

\begin{tabular}{|c|c|c|c|c|c|c|}
\hline samples & $1 / \mathrm{T}^{\circ}\left(k^{-1}\right)$ & Lin $K$ & $\Delta G$ & $\Delta \mathrm{H}$ & $\Delta \mathrm{S}$ & $R^{2}$ \\
\hline \multirow{4}{*}{$\begin{array}{l}60 \% \mathrm{OS} \\
40 \% \mathrm{DP}\end{array}$} & 0,0034 & 1,56 & -4.745 & \multirow{4}{*}{62.352} & \multirow{4}{*}{$229.10^{-3}$} & \multirow{4}{*}{0,762} \\
\hline & 0,0033 & 1,67 & -7.035 & & & \\
\hline & 0,0032 & 2,06 & -9.325 & & & \\
\hline & 0,0031 & 4,028 & -11.615 & & & \\
\hline \multirow{4}{*}{$\begin{array}{l}66 \% \mathrm{OS} \\
34 \% \mathrm{DP}\end{array}$} & 0,0034 & 1,58 & -4.8108 & \multirow{4}{*}{46.640} & \multirow{4}{*}{$175,6.10^{-3}$} & \multirow{4}{*}{0,776} \\
\hline & 0,0033 & 1,704 & -6.5668 & & & \\
\hline & 0,0032 & 1,984 & -8.135 & & & \\
\hline & 0,0031 & 3,43 & -9.885 & & & \\
\hline \multirow{4}{*}{$\begin{array}{l}85 \% \mathrm{OS} \\
15 \% \mathrm{DP}\end{array}$} & 0,0034 & 1,6 & -4.51 & \multirow{4}{*}{39.44} & \multirow{4}{*}{$150,7 \cdot 10^{-3}$} & \multirow{4}{*}{0,835} \\
\hline & 0,0033 & 1,67 & -6.01 & & & \\
\hline & 0,0032 & 2,07 & -7.51 & & & \\
\hline & 0,0031 & 3,11 & -9.01 & & & \\
\hline \multirow{4}{*}{$\begin{array}{l}80 \% \text { OS } \\
20 \% \text { DP }\end{array}$} & 0,0034 & 1.58 & -2.791 & \multirow{4}{*}{50.535} & \multirow{4}{*}{$182.10^{-3}$} & \multirow{4}{*}{0.762} \\
\hline & 0,0033 & 1.63 & -4.611 & & & \\
\hline & 0,0032 & 1.975 & -6.431 & & & \\
\hline & 0,0031 & 3.491 & -8.251 & & & \\
\hline \multirow{4}{*}{$\begin{array}{l}88 \% \mathrm{OS} \\
12 \% \mathrm{DP}\end{array}$} & 0.0034 & 1.61 & -2.984 & \multirow{4}{*}{50.635} & \multirow{4}{*}{$183.10^{-3}$} & \multirow{4}{*}{0.789} \\
\hline & 0.0033 & 1.68 & -4.814 & & & \\
\hline & 0.0032 & 2.07 & -6.644 & & & \\
\hline & 0.0031 & 3.51 & -8.474 & & & \\
\hline \multirow{4}{*}{$\begin{array}{c}100 \% \mathrm{DP} \\
0 \% \mathrm{OS}\end{array}$} & 0.0034 & 1,55 & -4.687 & \multirow{4}{*}{47.760} & \multirow{4}{*}{$179.10^{-3}$} & \multirow{4}{*}{0.820} \\
\hline & 0.0033 & 1,63 & -6.477 & & & \\
\hline & 0.0032 & 2,08 & -8.267 & & & \\
\hline & 0.0031 & 3,39 & -10.057 & & & \\
\hline \multirow{4}{*}{$\begin{array}{c}100 \% \mathrm{OS} \\
0 \% \mathrm{DP}\end{array}$} & 0,0034 & 1,554 & -2.688 & \multirow{4}{*}{47.708} & \multirow{4}{*}{$172,9 \cdot 10^{-3}$} & \multirow{4}{*}{0,825} \\
\hline & 0,0033 & 1,66 & -4.408 & & & \\
\hline & 0,0032 & 2,07 & -6.409 & & & \\
\hline & 0,0031 & 3,33 & -7.848 & & & \\
\hline
\end{tabular}

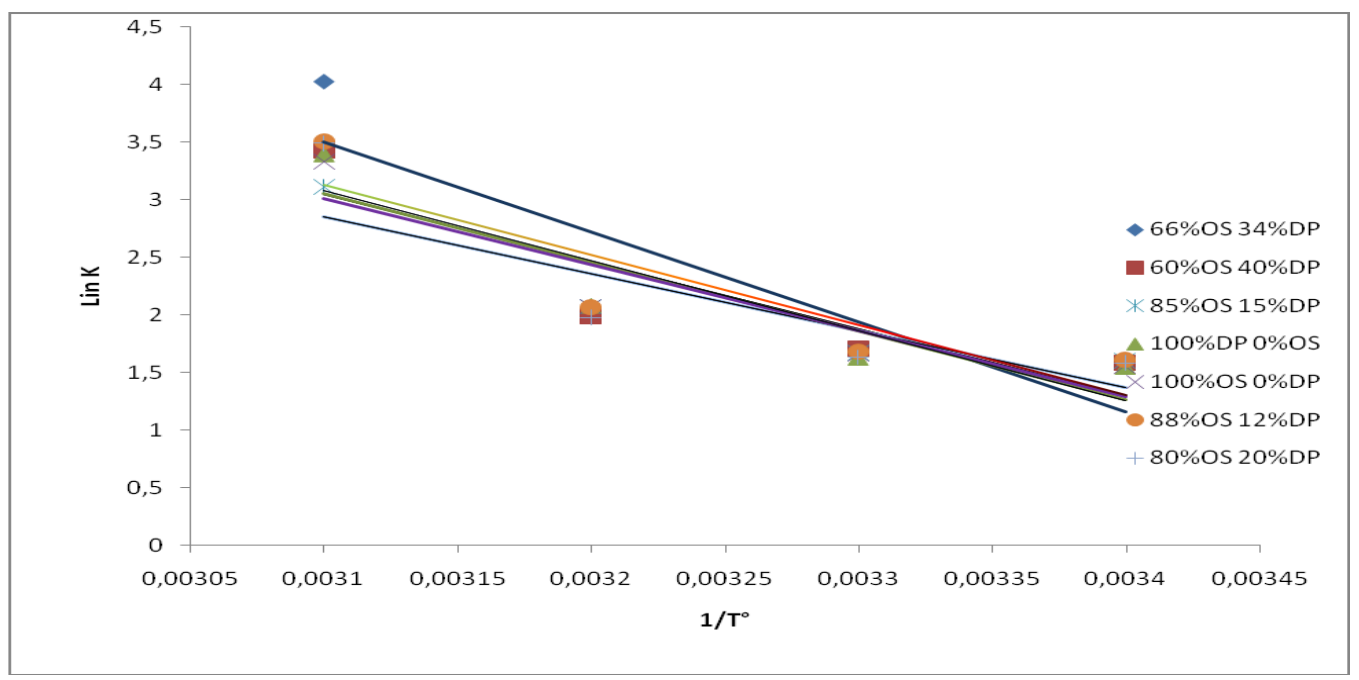

Fig. 10. The plot of $\ln \mathrm{K}_{\mathrm{L}}$ versus $1 / \mathrm{T}$ for the estimation of thermodynamic parameters. 


\section{CONCLUSION}

In this investigation, the mixture biosorbent (date pits and olive stones)as a low-cost natural adsorbent was studied for adsorptive removal of BY HE-4G from aqueous solution in batch mode. The results of adsorption showed that mixture biosorbent can be effectively used as a biosorbent for the removal of anionic dye. Adsorption of BY HE-4G was favored by a decrease in $\mathrm{pH}$.

The kinetics studies of dyes on biosorbent mixtures followed the pseudo-second- order at different mixture biosorbent. The equilibrium data have been analyzed, the results showed that the BY HE-4G followed Freudlich isotherm. The thermodynamic studies indicated that the adsorption was spontaneous and endothermic.

All these results indicated that the biosorbent mixture could be used as an adsorbent for textile wastewater treatment and it may be an alternative to more costly adsorbent.

\section{References}

[1] A.Gurses, C. Dogar, M.Yalcin, M.Acikyildiz, R.Bayrak, S.Karaca. The adsorption kinetics of cations dye, methylene blue, onto clay, J. Hazard. Mater. B131 (2006) 217228.

[2] T. Robinson, G. McMullan, R. Marchant, P. Nigam, Removal of dyes from a synthetictextile dye effluent by biosorption on apple pomace and wheat straw. Water Res. 36(2002) 2824-2830.

[3] M. P.Elizalde-Gonzalez, V. Hernandez-Montoya. Removal of acid orange 7 by guava seed carbon: A four parameter optimization study. J. Hazard. Mater. 168 (2009) 515522.

[4] Soares GMB, Amorim MTP, Hrdina R, M.Costa-Ferreira. Studies on the biotransformation of novel diazo dyes by laccase. Process Biochem. 581(2002) 7-37.

[5] A. Gucek, S.Sener, S.Bilgen, M.A. Mazmanci, adsorption and kinetic studies of cationic and anionic dyes on pyrophyllite from aqueous solutions, J. Colloid Interface Sci.286(2005) 53-60.

[6] S. Karthikeyan, R. Balasubramanian, C.S.P. Lyer. Evaluation of the marine algae Ulva fasciata and Sargassum sp.for the biosorption of $\mathrm{Cu}(\mathrm{II})$ from aqueous solutions. Bioresour. Technol. 98(2007) 452-455.

[7] T.Robinson,B.Chandron and P.Nigam,Removal of dyes from a synthetic textile dye effluent by biosorption on apple pomace and wheat straw.Water Res.,36(2002)28242830 .

[8] Zeynep Eren,Filiz Nuran Acar ; Adsorption of Reactive Black 5 from an aqueous solution :equilibrium and kinetic studies. Desalination 194(2006) 1-10.

[9] N.Barka; S.Qourzal ;A.Assabbane;A.Nounah;Y.Ait-Ichou. Removal of Reactive Yellow 84 from aqueous solutions by adsorption onto hydroxyapatite. Journal of Saudi Chemical Society.(2010) 
[10]Y.Safa, H.Nawaz Bhatti. Adsorptive removal of direct textile dyes by low cost agricultural waste: Application of factorial design analysis. Chemical Engineering Journal 167(2011)35-41.

[11]T.Akar,I.Tosun,Z.kaynak,E.Ozkara,O.Yeni.An Attractive Agro-industial by - product in environmental cleanup: Dye biosorption ootential of untreated olive pomace. J.of Hazard. Mater. 166(2009) 1217-1225.

[12]N.ERTUGAY, Y.K. Bayhan. Biosorption of Cr (VI) from aqueous solutions by biomass of Agaricus bisporus ,J.Hazard.Mater. 154(2008) 432-439.

[13]T. Akar, I.Tosun, Z.Kaynak, E.Kavas, G.Incirkus, S.T.Akar. assessment of the biosorption characteristics of a macro-fungus for the decolorization of Acid Red 44(AR44) dye ,J.Hazard.Mater. 17152009 865-871.

[14]A.Khled,A.ElNemr, A.El Sikaily, O.Abdelwahab. Treatment of artificial textile dye effluent containing Direct Yellow 12 by orange peel carbon. Desalination 238(2009) 210-232. 